\title{
Voters Perception on Gender Equity in Public Elections in Makassar City, Indonesia
}

\author{
${ }^{1}$ Syamsiah Badruddin, ${ }^{2}$ Paisal Halim, ${ }^{3}$ Zulkarnain Hamson \\ ${ }^{1,2,3}$ Lecturer \\ ${ }^{1}$ Post Graduate Program, Institut of Social and Management (STIAMI), Jakarta, Indonesia \\ ${ }^{2}$ Faculty of Administration, Institut of Social and Management (STIAMI), Jakarta, Indonesia \\ ${ }^{3}$ Social and Political Science Faculty, Universitas Indonesia Timur, Makassar, Indonesia
}

\begin{abstract}
The quality of public election is an indicator of the progress of democratization of a nation. Gender equality becomes one of the supporters of the quality of the administration of elections. This article outlines voters' perceptions of gender equity in elections. The benefits of this study are the basic ingredients for the development of democratization in Indonesia. The study involved 100 respondents were chosen by purpossive sampling. The rspondents are women voters in Makassar City at Public Election 2014. The results show that the low gender equality in elections is due to the low communication of women candidates. Voters generally do not know about candidate figures and political culture.
\end{abstract}

Keywords : Candidate, politic communication and perception.

\section{INTRODUCTION}

The development of government systems in the last three decades in many countries is the fall of the authoritarian regime and the development of a democratic system[1]. The democratic system in Indonesiawas also changing in 2014 by change in the electoral system. Elections are a political institution that leads to social, political and economic tendencies and becomes an indicator of the democratic sustainability of a nation [2].National Regulatianof Indonesia No. 15 Year 2011 on the holding of elections reinforces the government's desire to improve the quality of general elections. Qualified general elections run directly, publicly, freely, confidentially, honestly and fairly. One form of justice in the general election is the existence of equality between women and men.

Based on National Regulation No. 8 Year 2012, there is a rule of woman proportion in legislative. The percentage of women candidate in the election of regional legislative members as much as $30 \%$. Juridical, there are gender equality efforts in elections. However, the number of women candidates elected as legislators is still below the $30 \%$ quota. However, the existence of regulatory instruments does not significantly affect the quantity of women's political representation in parliament. This is due to the perception of voters who have not entrusted their political role in women candidates. Gender issues also appear in the general elections in Makassar City 2014. Local parliamentarians are 50 and there are only seven women from 11 parties. The fact shows that there are only 12 percent of women in local parliaments or have not met the requirements of gender equality. In fact, the number of voters is crucial to the election results. Furthermore, the perception of voters determine the gender equity in the general election.

Such perception is born from information obtained from women candidates. If women candidates are able to demonstrate good political strategy and communication, then the perception of choosing women candidates is also high. Based on the case, this study reveals the perception of women voters to gender equity in general election in Makassar City. The results of this study form the basis for determining the strategy and political communication of women candidates in the upcoming 2019 general election

\section{THEORETICAL REVIEW}

\section{Political Strategy}

Strategy or plan is a reference action that selected in the achievement of goals. In a political context, strategy is an important part of showing political power to attract voters [3]. Political strategies can build a voter perspective that is promoted by politicians or candidates. The strategy aims to expose the ability of candidates who are built with emotional closeness with and voters [4].

There are four choices of political strategy namely reinforment strategy, rationalization strategy. Inducement strategy and cconfrontation strategy. Reinforment strategy is a contestant strategy that prioritizes the image or political performance. With the image built long ago, then the candidate won public trust. Rationalization strategy or candidate approach to change voters' perceptions of other candidates who have a negative performance or image. Inducement strategy is the strategy develops the perception of voters by using appropriate attributes with the community. Confrontation strategy influence people do not choose other candidate [5].

\section{Politic Communication}

Political communication is one of the strategies that play a role in the success of the candidate. In the context of elections, political communication has a central role to achieve a large turnout, political communication strategies appear in candidate activity in raising its popularity[6]. Socialization of effective vision and mission in various ways is an attempt to influence voters' minds. 


\section{Voters Perception}

The definition of perception is the result of brain interpretation of the stimulus received by the human sense apparatus. Interpretation results can be positive or negative and may affect human actions. In the context of elections, voter perceptions are based on stimuli received by the brain[7]. The stimulus is information about the candidate profile. If the candidate is able to provide interesting information about his political history as well as the idea of community development, then the voter's perception is positive. On the other hand, if the voters do not get candidate information, then the perception is negative. The results of thought or perception influence voter decision.

Specifically, women candidates should be able to form a good stimulus on voters. A good stimulus can be formed by intensive communication with voters.

\section{METHOD}

The focus of the research is the public perception on gender equity for case studies on local legislative elections in 2014. This study is a quantitative survey involving 100 respondents. Determination of respondents by purposive sampling method with the following considerations: 1) registered as voters; 2) Women and 3) As residents of Makassar City. Implementation of research in January - February 2017. Method of data analysis using frequency analysis and percentage.

\section{RESUlT AND DiscuSS}

\section{Respondent Characteristic}

Figure 1, figure 2 and figure 3 show respondent characteristics about age, educational background and ability to access information.

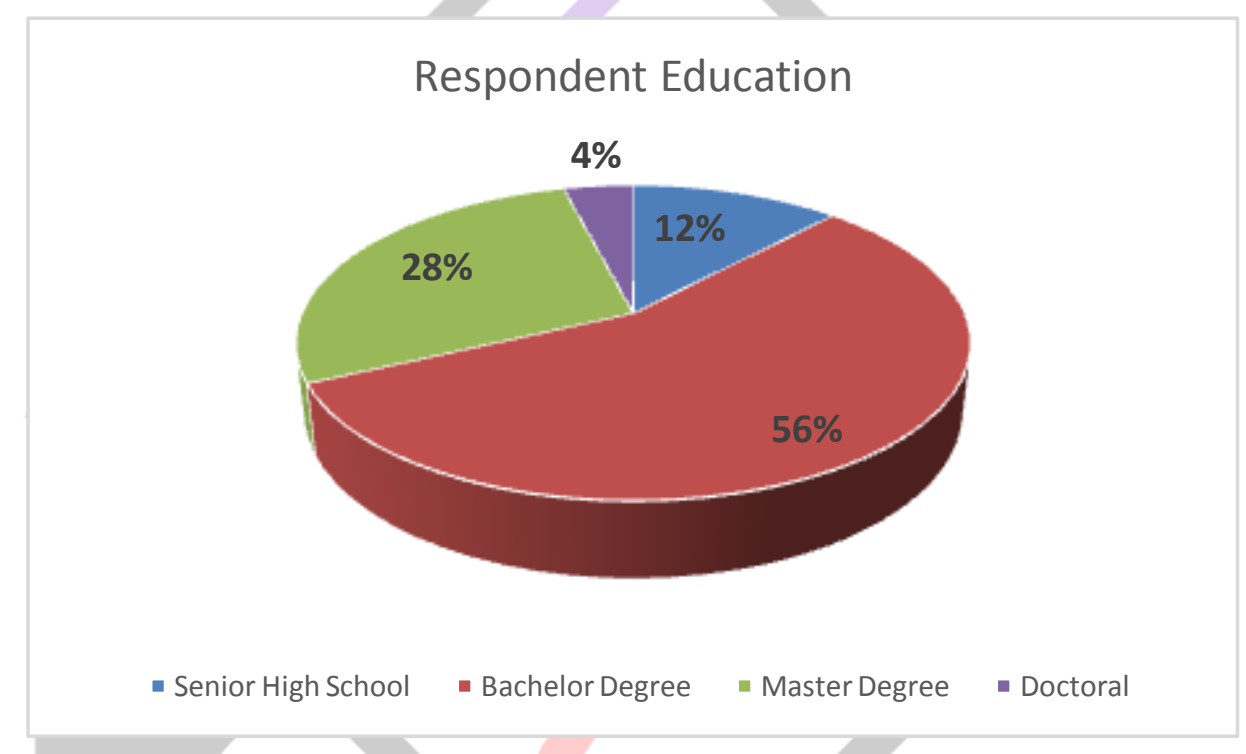

Fig 1: The respondent education

\section{The age of respondent}

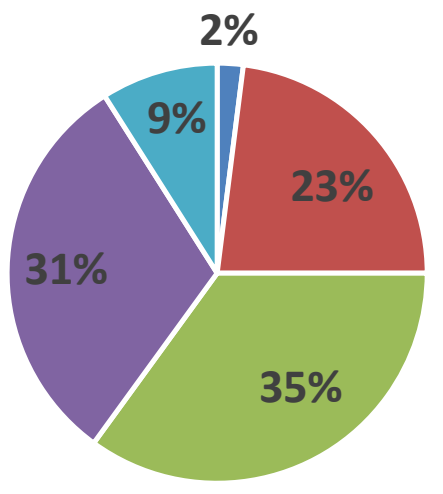

- Less than $22 \quad$ - $22-30 \quad-30-40 \quad-40-50 \quad$ - More than 50

Fig 2: The age of respondent 


\section{Information Acces Knowledge}

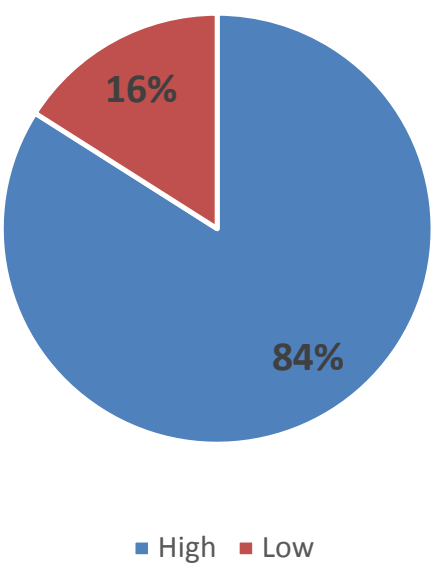

Fig3: The Information Access Knowledge of Respondent

Figure 1 shows that most of the respondents are educational background (56\%) and only $4 \%$ have doctorate degree. A person's educational background affects his perceptions to make his choices. The higher a person's education, the decision to choose based on rational considerations. The data is related to the age of respondent. Figure 2 shows the age distribution of respondents. The analysis results show that the age of respondents is mostly between 30 years - 40 years (35\%) and there are $31 \%$ of respondents with age between 40 years - 50 years. The age of a person determines the decision to elect a candidate in parliament. The age of over 30 indicates that the respondent has experienced voter experience in the general electorate. With such experience, voters have attention to candidate figures and competencies.

Figure 3 shows the ability of respondents to access information. A person's ability to access information over the internet or have the daily reading of newspapers indicates a high degree of ability. Being for respondents who are unable to access information via the internet and newspapers indicate a low ability. The results show that $84 \%$ of respondents have the ability to access information. Factually, people who choose the habit of accessing information via the internet or newspapers get a picture of more candidates. Information about the candidate impacts the election's decision.

\section{Participation on Public Election}

Respondents who are voters in the 2014 elections have the right to determine their participation. There are $92 \%$ of the respondents who voted for the vote. This fact shows that respondents have good political participation to determine the right candidate in the local parliament. (Table 1).

Table 1 Respondent participation on public election 2014

\begin{tabular}{|r|c|r|r|}
\hline No & Vote participation & Frequency & \multicolumn{1}{|c|}{ Percentage } \\
\hline 1 & Vote & 92 & $92 \%$ \\
\hline 2 & No vote & 8 & $8 \%$ \\
\hline
\end{tabular}

Candidates' selection decision based on perception of voters. A voter's understanding of the character of a female candidate affects her perception. The more information received, the community will determine the number of voters. Table 2 shows the percentage of perceptions about the character of women candidates

Table 2 Respondent's perception of female legislative candidate character

\begin{tabular}{|r|c|r|r|}
\hline No & $\begin{array}{c}\text { Character of the legislative } \\
\text { candidate }\end{array}$ & Frequency & Percentage \\
\hline 1 & Know & 23 & $23 \%$ \\
\hline 2 & Not know & 77 & $77 \%$ \\
\hline
\end{tabular}

Table 2 shows that $77 \%$ of respondents did not know about female legislative candidate character. Such perceptions are based on the fact that voters receive information about candidates through program campaigns. Personal interaction between voters and candidates is very limited. 
Figure candidates based on their history in social activities. Candidates with intensity in community activities will shape good voter perceptions. Table 3 shows that $84 \%$ of respondents do not know about candidate figures.

Table 3 Respondent's perception about female legislative candidate figure

\begin{tabular}{|r|c|r|r|}
\hline No & $\begin{array}{c}\text { Gender } \\
\text { perception on vote }\end{array}$ & Frequency & \multicolumn{1}{c|}{ Percentage } \\
\hline 1 & Women & 5 & $5 \%$ \\
\hline 2 & Men & 35 & $35 \%$ \\
\hline 3 & $\begin{array}{c}\text { No difference } \\
\text { between men and } \\
\text { women }\end{array}$ & 58 & $58 \%$ \\
\hline 4 & Not know & 2 & $2 \%$ \\
\hline
\end{tabular}

The political culture of the candidate greatly affects the perception of the electorate. Candidate competence develops based on the political culture built by candidates over a long period of time. Candidates with good political experience will influence voter perceptions. However, based on the results of the study (Table 5), most of the respondents (84\%) were unaware of the political culture of women legislative candidates.

Table 5 Perceptions of respondents about the political culture of women legislative candidates

\begin{tabular}{|r|c|r|r|}
\hline No & $\begin{array}{c}\text { The political culture of } \\
\text { women legislative } \\
\text { candidates }\end{array}$ & Frequency & Percentage \\
\hline 1 & Know & 16 & $16 \%$ \\
\hline 2 & Not know & 84 & $84 \%$ \\
\hline
\end{tabular}

Political culture is the main information about the ability of candidates in politics. The community is very hopeful of channeling interests and aspirations through candidates. The perception of political culture of women candidates is very low based on the lack of information about women's activities.

Political communication is a candidate's strategy to introduce his political history and vision. Table 6 shows that $88 \%$ of respondents do not know about political communication in women's candidates. This indicates that the political strategy of women candidates has not appeared specifically to women voters.

Table 6 Perception of respondents about political communication of legislative candidates

\begin{tabular}{|r|c|r|r|}
\hline No & $\begin{array}{c}\text { Political communication } \\
\text { of legislative candidates }\end{array}$ & Frequency & \multicolumn{1}{c|}{ Percentage } \\
\hline 1 & Know & 12 & $12 \%$ \\
\hline 2 & Not know & 88 & $88 \%$ \\
\hline
\end{tabular}

The results showed that the perception of voters on gender equity is still very minimal. This is due to the lack of information about the character, figure and political culture of women candidates. Most of the information that develops in society about electoral candidates is dominated by male candidates. This is a challenge for women candidates to be able to raise the electability. Political communication that can affect women voters is to build networks and activities by broadening gender equality.

\section{DISCUSSION}

Gender equality in elections in Makassar City as a parameter of low public confidence in women candidates. Political campaigns are crucial to the choice of people's votes. The wider influence on political learning and perception control depends on the candidate's interaction strategy with the community. The campaign information model with the message content design and the predisposing of the recipient should be the candidate's consideration. This is based on the fact that the campaign effect on the use of the new methodology will be more effective[6]

Efforts to improve women's electiveness also consider women's voter ability in information search. Women searching for information about their candidates are heavily influenced by the campaign strategy. The more information related to the competence of women candidates than male candidates will influence voter choice. Public perception begins with information about candidates to make an evaluation of candidates [8].

Based on the results of the research, for women candidates should develop their political communication skills. Political communication is a tool to attract the attention of voters and influence the political environment. By him, communications must be in accordance with the characteristics of voters. Currently, candidates can create blogs or other social media [9]. 


\section{ConCluSION}

Public perceptions of gender equality in elections are still low which is marked by the low interest of women voters in choosing women candidates. The candidate's political strategy should be able to increase voter knowledge about his political figure and culture. Political communication by women candidates should be more attractive to the attention of the electorate.

\section{REFERENCES}

[1] G. Boushey, Policy diffusion dynamics in America. Cambridge University Press, 2010.

[2] C. Rallings, M. Thrasher, and D. Cowling, "Mayoral referendums and elections," Local Gov. Stud., vol. 28, no. 4, pp. 6790, 2002.

[3] C. M. Christensen, How Will You Measure Your Life?(Harvard Business Review Classics). Harvard Business Review Press, 2017.

[4] M. J. Burton, W. J. Miller, and D. M. Shea, Campaign Craft: The Strategies, Tactics, and Art of Political Campaign Management: The Strategies, Tactics, and Art of Political Campaign Management. ABC-CLIO, 2015.

[5] J. N. Sheth and G. L. Frazier, “A model of strategy mix choice for planned social change,” J. Mark., pp. 15-26, 1982.

[6] S. Iyengar and A. F. Simon, "New perspectives and evidence on political communication and campaign effects," Annu. Rev. Psychol., vol. 51, no. 1, pp. 149-169, 2000.

[7] C. Sergent, S. Baillet, and S. Dehaene, "Timing of the brain events underlying access to consciousness during the attentional blink," Nat. Neurosci., vol. 8, no. 10, p. 1391, 2005.

[8] T. M. Ditonto, A. J. Hamilton, and D. P. Redlawsk, "Gender stereotypes, information search, and voting behavior in political campaigns," Polit. Behav., vol. 36, no. 2, pp. 335-358, 2014.

[9] B. McNair, An introduction to political communication. Taylor \& Francis, 2017.

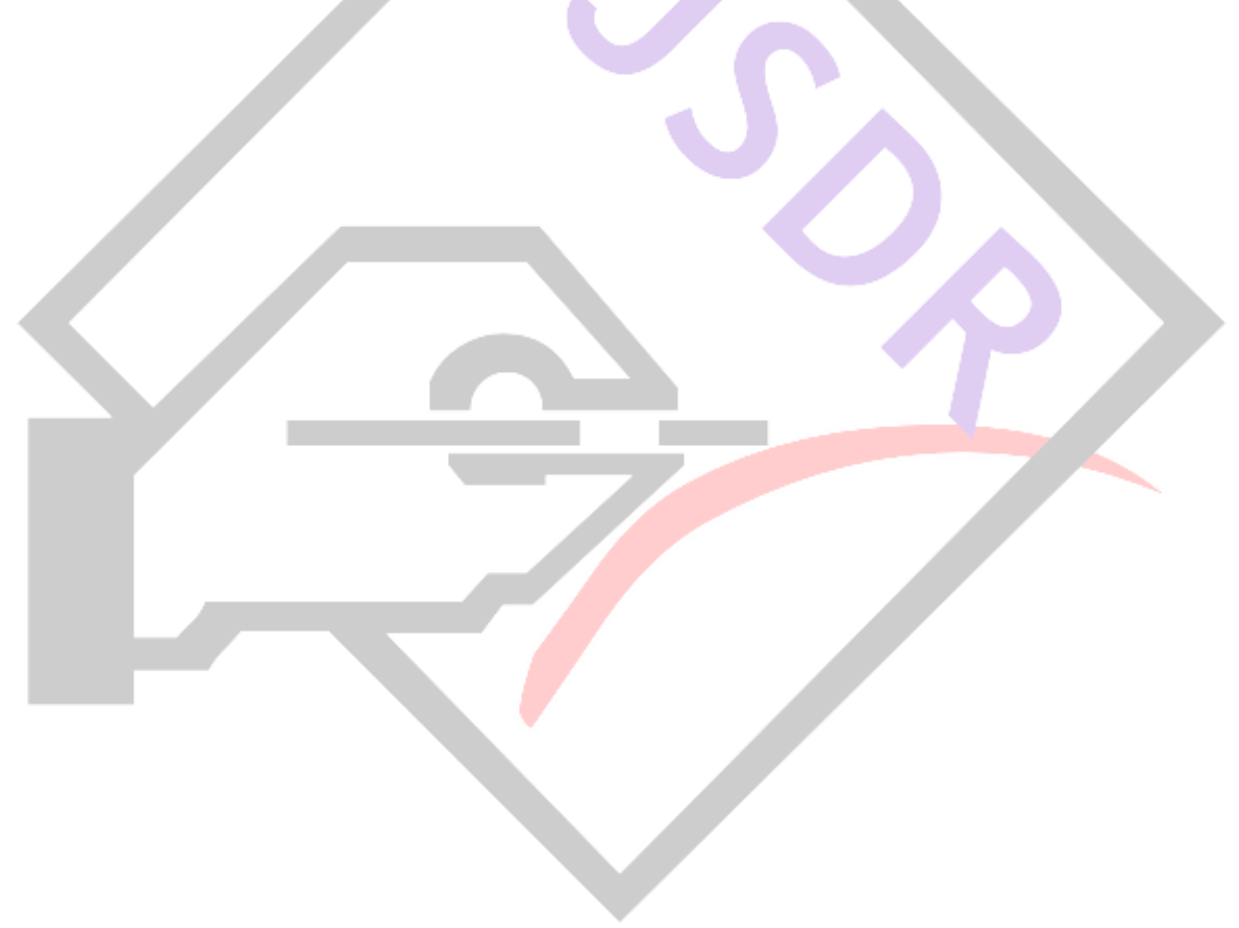

